\title{
A NEW TECHNIQUE FOR RECORDING COMPLIANCE OF HUMAN HAND VEINS
}

\author{
W.H. AELLIG \\ Experimental Therapeutics Department, \\ Clinical Research Division, Sandoz Ltd, Basle, Switzerland
}

1 A new technique for determining venous compliance at a standardized congestion pressure has been developed based on the optical method described by Nachev, Collier \& Robinson (1971). It uses a linear variable differential transformer for a direct and continuous recording of venous compliance.

2 This method has been used to establish dose-response curves for the constrictor effects of noradrenaline, adrenaline, 5-hydroxytryptamine and dihydroergotamine after direct local infusion.

3 A parallel shift to the right of the noradrenaline dose-response curves was observed after local infusion of phentolamine, showing that the method can be used also to study interactions between agonists and antagonists on human veins in vivo.

4 The usefulness of this technique for investigating the effects of orally administered drugs has also been established. The venoconstrictor action of dihydroergotamine reached its maximum after $1.5 \mathrm{~h}$ and remained almost constant for the period of observation $(8 \mathrm{~h})$.

\section{Introduction}

The various methods available for the assessment of drug effects on the venous system in man have recently been reviewed by Robinson (1978) in this journal. For studies of direct drug effects and drug interactions on single human veins in vivo, two different kinds of method are currently used. One is the venoconstriction test described by Sicuteri, Del Bianco, Fanciullacci \& Franchi (1964) and its computerized version (Del Bianco \& Sicuteri, 1978). It is based on pressure measurements in a dorsal vein of the hand or wrist before and after local infusion of drugs producing venospasm.

The other method is the optical one developed by Nachev et al. (1971). It relies on the measurement of changes in venous diameter at a constant venous pressure. In its original version the diameter of the vein is determined by an optical method. Modifications of this technique have been developed with the aim of recording venous diameter using an electromechanic device. Aminu \& Vere $(1972,1978) \mathrm{em}$ ployed a small capacitor with one plate resting on a superficial hand vein and the other on the skin beside the vein. White \& Udwadia (1975) placed the arm of a displacement transducer over a marked spot on the vein.

A new and relatively simple technique for recording venous compliance has been developed. It relies on the same basic principle of determining venous diameter at a given congestion pressure as the optical method. It is based on the use of a linear variable differential transformer mounted directly on the back of the hand. An abstract of this method has been published previously in this journal (Aellig, 1979).

\section{Methods}

\section{Subjects}

All experiments were carried out in healthy male volunteers. Written informed consent was obtained after full explanation of the experimental procedures involved. Details of the subjects are given in Table 1.

\section{Linear variable differential transformer}

A linear variable differential transformer (Schaevitz, 1947) is an arrangement of three identical coils of which the central primary one is energized by an alternating current. The two outer, secondary coils are connected in serial opposition, so that the sum of the voltages induced is zero. With a steel core placed in the central aperture of the transformer, the voltage is zero if the core is in a central position. The resultant voltage changes when the core is displaced, and these alterations are linearly proportional to the displacement. In our experiments, a Schaevitz type 025 MHR differential transformer was employed. For the power supply, the amplification and the conversion of the AC output to a DC output, a Schaevitz modular 
Table 1 Details of subjects

\begin{tabular}{rcccc}
\hline Subject & Sex & $\begin{array}{c}\text { Age } \\
\text { (years) }\end{array}$ & $\begin{array}{c}\text { Body } \\
\text { weight } \\
(\text { kg) }\end{array}$ & $\begin{array}{c}\text { Height } \\
\text { (cm) }\end{array}$ \\
1 & M & 25 & 65 & 176 \\
2 & M & 24 & 72 & 188 \\
3 & M & 22 & 65 & 176 \\
4 & M & 24 & 69 & 183 \\
5 & M & 22 & 72 & 192 \\
6 & M & 40 & 79 & 179 \\
7 & M & 24 & 71 & 178 \\
8 & M & 24 & 69 & 172 \\
9 & M & 23 & 71 & 171 \\
10 & M & 27 & 75 & 181 \\
11 & M & 23 & 72 & 183 \\
12 & M & 25 & 74 & 182 \\
13 & M & 29 & 76 & 176 \\
14 & M & 29 & 64 & 172 \\
15 & M & 27 & 74 & 177 \\
16 & M & 27 & 81 & 193
\end{tabular}

LVDT signal conditioner type LPM $2102.5 \mathrm{kHz}$ was used. The DC output was recorded with the aid of a potentiometric recorder. This device can be exactly calibrated, thus allowing the continuous recording of the exact position of the central core of the transformer.

\section{Hand vein measurements}

Measurements were taken with the subjects resting in the flat supine position. An arm was placed on a rigid support sloping upwards at an angle of $30^{\circ}$ from the horizontal. This allowed complete emptying of the superficial hand veins. A suitable vein on the dorsum of the hand was then chosen after inflation to $45 \mathrm{~mm}$ $\mathrm{Hg}$ of a sphygmomanometer cuff placed on the upper arm. With the aid of a small tripod, the linear variable differential transformer was mounted on the back of the hand with its central aperture over the vein under investigation. The light steel core weighing $0.5 \mathrm{~g}$ and situated in the central aperture of the transformer, was placed over the summit of the vein under investigation. The sphygmomanometer cuff was then deflated.

Continuous recordings of the position of the core situated over the summit of the vein were made before and after inflation of the sphygmomanometer cuff to $45 \mathrm{~mm} \mathrm{Hg}$. The difference between the two positions of the core is a measure of the diameter of the studied vein under a congestion pressure of $45 \mathrm{~mm} \mathrm{Hg}$. Figure 1 shows a diagram of the experimental set up. Figure 2 shows an actual recording.

For the determination of venous diameter during local drug infusions, the occlusion cuff was inflated for the last $2 \mathrm{~min}$ of each infusion period of $5 \mathrm{~min}$ (see below). Noradrenaline dose-response curves were obtained in addition during continuous inflation of the sphygmomanometer cuff for the whole infusion period.

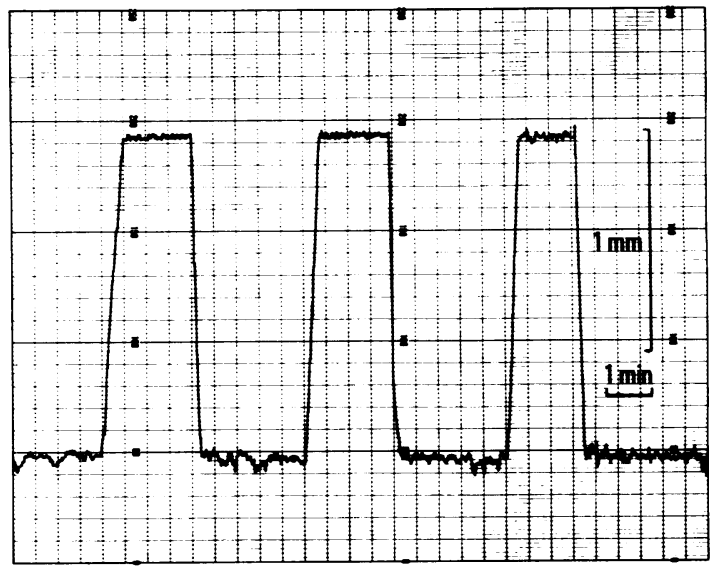

Figure 2 Registration of the position of the central core, i.e. the summit of the studied vein, before and after inflation of the cuff to $45 \mathrm{~mm} \mathrm{Hg}$.
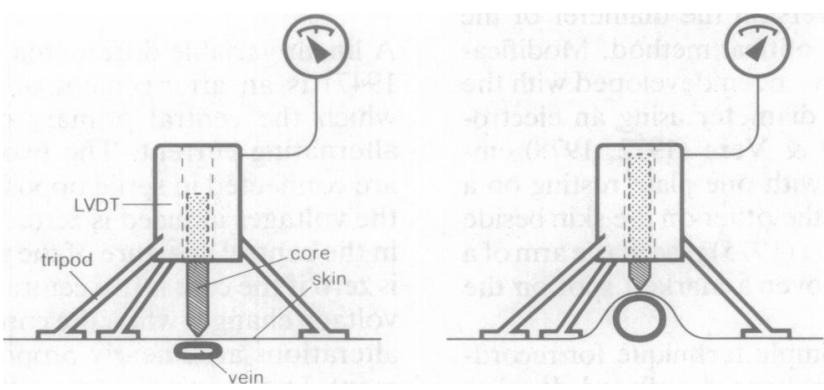

Figure 1 Diagram of the experimental set up. On the left the metal core stands over the empty vein and on the right over the vein dilated during inflation of a sphygomanometer cuff placed on the upper arm to $45 \mathrm{~mm} \mathrm{Hg}$. LVDT= linear variable differential transformer). 


\section{Local drug infusions}

For the investigation of direct drug effects, a small needle $(27 \mathrm{G})$ from a lymphangiography set was inserted into the vein about $10 \mathrm{~mm}$ distal to the site of measurement. Immediately after the insertion of the needle, a continuous infusion of physiological saline was started in order to prevent the blocking of the needle, but also to carry out control determinations of venous diameter under the same conditions as during drug infusions. For saline infusions, a volume of $0.1 \mathrm{ml} / \mathrm{min}$ was chosen. During local drug infusions, saline was replaced by drug solutions in physiological saline. Concentrations were used which allowed to administer the desired doses in infusion volumes of 0.1 or $0.2 \mathrm{ml} / \mathrm{min}$.

When dose-response curves were being established, the first dose was always given in an infusion volume of $0.1 \mathrm{ml} / \mathrm{min}$. For doubling the dose, the infusion volume was increased to $0.2 \mathrm{ml} / \mathrm{min}$. For the next higher dose, a higher concentration of the drug was used, again in an infusion volume of $0.1 \mathrm{ml} / \mathrm{min}$, and so on. All drug dosages are expressed as the equivalent of the base. Noradrenaline hydrochloride, adrenaline hydrogentartrate and 5-hydroxytryptamine creatinine sulphate infusions were administered in the following doses: 2, 4, 8, 16 and $32 \mathrm{ng} / \mathrm{min}$. Each dose was given during $5 \mathrm{~min}$.

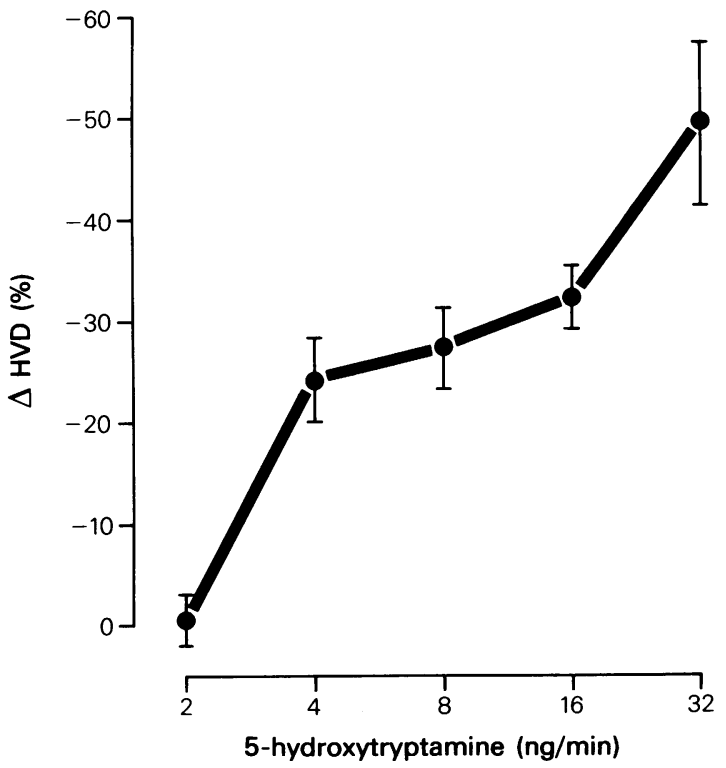

Figure 3 Dose-response curve for the venoconstrictor effect of 5-hydroxytryptamine during local infusion into superficial hand veins. The ordinate shows the reduction of hand vein diameter (HVD) at a cuff pressure of 45 $\mathrm{mm} \mathrm{Hg}$ expressed as a percentage of the control value during saline infusion. (Mean \pm s.e. mean, $n=5$, subjects no. 1-5).
For dihydroergotamine methanesulfonate the doseresponse curve established was cumulative because of the long duration of action of this drug. Two different concentrations of dihydroergotamine $(0.5 \mu \mathrm{g} / \mathrm{ml}$ and $2 \mu \mathrm{g} / \mathrm{ml}$ ) were used and administered in infusion volumes of 0.1 and $0.2 \mathrm{ml} / \mathrm{min}$. Each dose was administered for $5 \mathrm{~min}$.

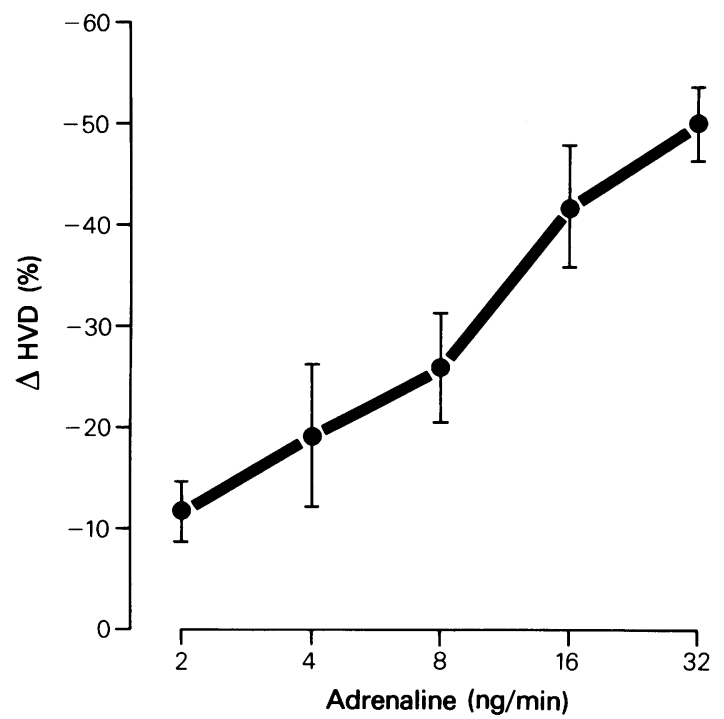

Figure 4 Dose-response curve for the venoconstrictor effect of adrenaline during local infusion into superficial hand veins. Details as in Figure 4, mean \pm s.e. mean, $n$ $=5$, subjects no. $1-5$.

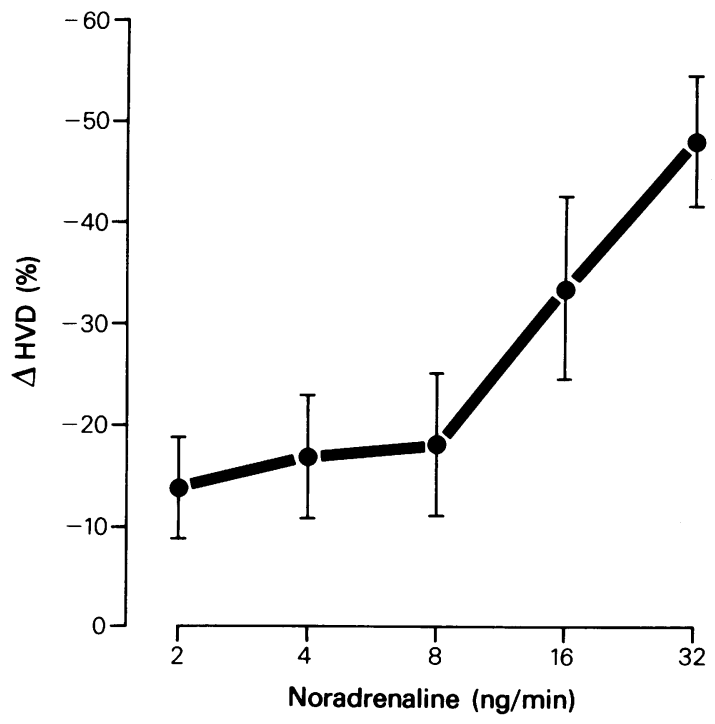

Figure 5 Dose-response curve for the venoconstrictor effect of noradrenaline during local infusion into superficial hand veins. Details as in Figure 4 , mean \pm s.e. mean, $n=5$, subjects no. $1-5$. 
To study the interactions between phentolamine and noradrenaline, dose-response curves for noradrenaline were established as described above, before and immediately after the local infusion of phentolamine chloride in a dose of $10 \mu \mathrm{g} / \mathrm{min}$ for 5 min (infusion volume $0.1 \mathrm{ml} / \mathrm{min}$ ).

\section{Oral drug administration}

The effects of orally administered dihydroergotamine and placebo were investigated in nine healthy volunteers. They received $10 \mathrm{mg}$ dihydroergotamine (Dihydergot) and placebo in a randomized doubleblind cross-over design with an interval of 1 week between the two administrations. No needle was inserted into the vein in these experiments and the period of measurement was extended to $8 \mathrm{~h}$.

\section{Results}

The new technique was well suited for the investigation of dose-response curves of the constrictor effect of various agonists on human hand veins in vivo. Figures 3, 4 and 5 show dose-response curves obtained

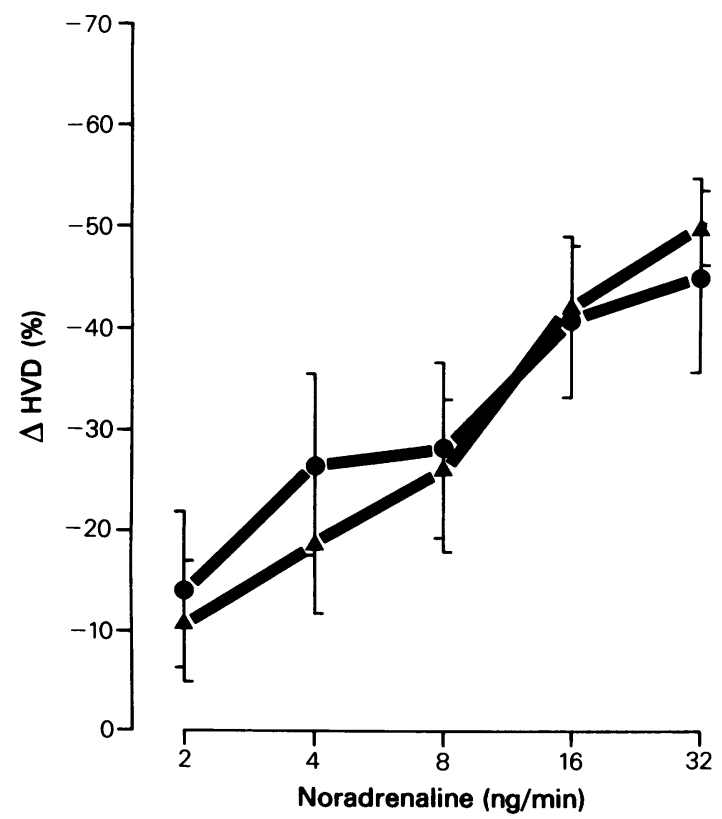

Figure 6 Dose-response curve for the venoconstrictor effect of noradrenaline during local infusion into superficial hand veins. Venous diameter (HVD) was determined either during continuous inflation of the sphygmomanometer cuff during the whole infusion period (A) or for the last $2 \mathrm{~min}$ of each infusion only (O). Details as in Figure 4, mean \pm s.e. mean, $n=5$, subjects no. 1-5. during local infusion of 5-hydroxytryptamine, adrenaline and noradrenaline respectively into superficial hand veins of five subjects. It is evident that, in the doses used, all compounds produced similar reductions in venous compliance.

When two different schedules for the inflation of the occlusion cuff (continuous inflation during the whole drug infusion and intermittent inflation for the last 2 min of each dose only) where compared in five subjects it was found that both of them lead to comparable dose-response curves for noradrenaline (Figure 6).

When noradrenaline dose-response curves were established in five volunteers before and after local infusion of $50 \mu \mathrm{g}$ of phentolamine, the expected parallel shift to the right could be observed (Figure 7).

The direct and dose-dependent venoconstrictor effect of locally infused dihydroergotamine in five subjects is shown in Figure 8 with cumulative doses ranging from 0.25 to $4 \mu \mathrm{g}$. A dose of $2 \mu \mathrm{g}$ leads to about the same effect as $32 \mathrm{ng} / \mathrm{min}$ of noradrenaline, adrenaline or 5-hydroxytryptamine.

Table 2 shows the changes in venous compliance after oral administration of $10 \mathrm{mg}$ dihydroergotamine and placebo. After oral placebo, venous compliance remained remarkably constant for the first $4 \mathrm{~h}$ after the administration; after $6 \mathrm{~h}$ and $8 \mathrm{~h}$ only small variations occurred. After oral dihydroergotamine a venoconstrictor effect was observed which reached its maximum at $1.5 \mathrm{~h}$ and remained practically constant until the end of the experiment $(8 \mathrm{~h})$, apart from the slightly but not significantly higher value at $4 \mathrm{~h}$.

\section{Discussion}

The results of the experiments presented here show that our new technique for recording compliance of human hand veins in vivo is well suited to the study of both the direct constrictor effects of drugs on human veins and the interactions between agonists and antagonists.

The dose-response curves obtained during local infusion of noradrenaline, adrenaline and 5-hydroxytryptamine show that the potency of these three drugs is about equal as far as their constrictor effects on human hand veins is concerned. This is in accordance with the results published by Collier, Nachev \& Robinson (1972) using the optical technique for measuring venous compliance.

The direct constrictor effect of dihydroergotamine seen on isolated human veins in vitro (MüllerSchweinitzer, 1974) and on superficial hand veins with the optical method (Aellig, 1974) could also be demonstrated in a dose-dependent way with our new technique.

The new technique described here has several advantages: The transformer can be mounted directly 


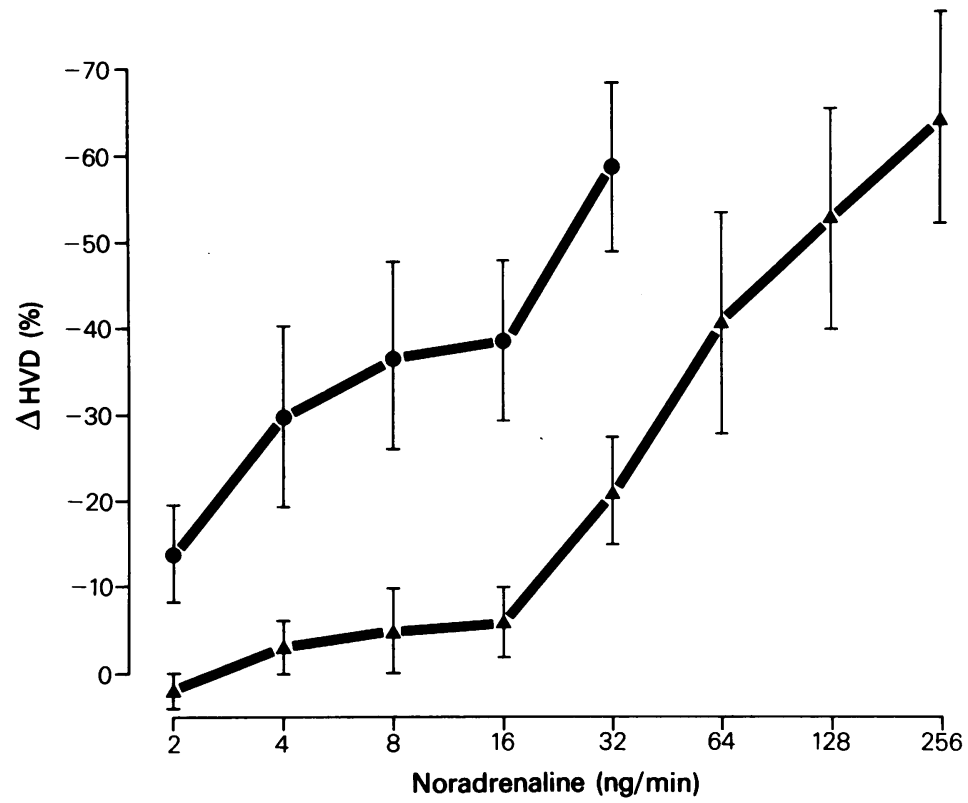

Figure 7 Dose-response curves for the venoconstrictor effect of noradrenaline during local infusion into superficial hand veins before $(O)$ and after $(\Delta)$ local infusion of $50 \mu \mathrm{g}$ phentolamine. Details as in figure 4 , means \pm s.e. mean, $n=5$, subjects, no. $1-5$.

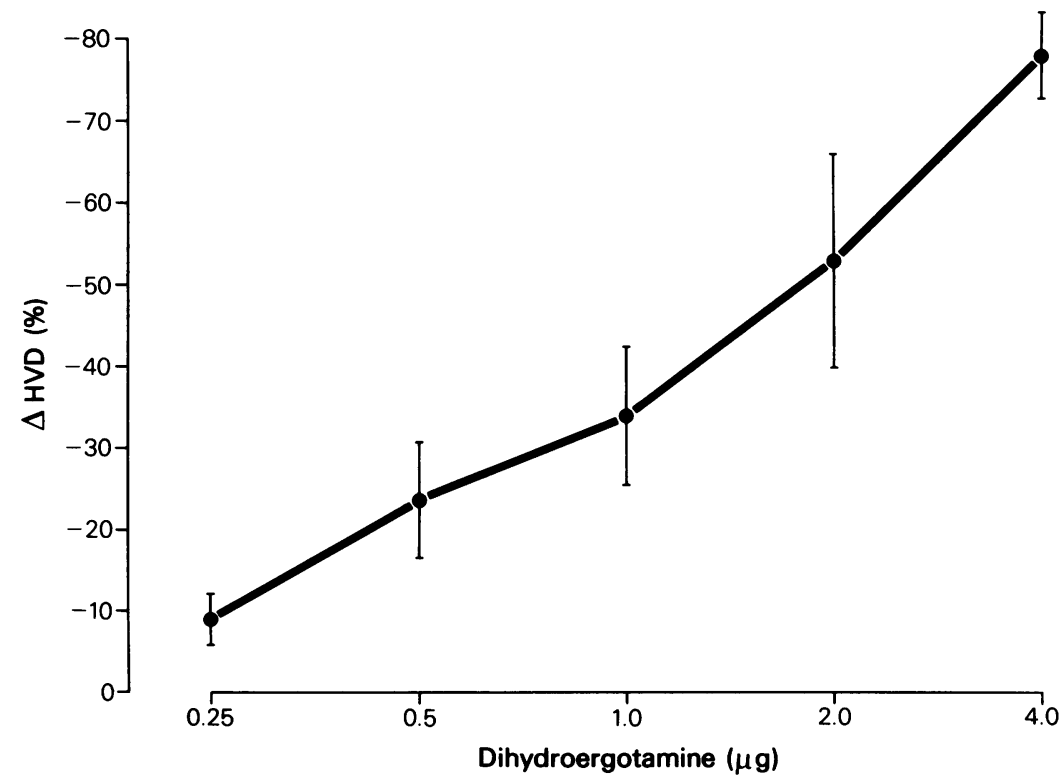

Figure 8 Cumulative dose-response curve for the venoconstrictor effect of dihydroergotamine infused locally into superficial hand veins. Details as in Figure 4, mean \pm s.e. mean, $n=5$, subjects no. 1, 2, 4, 6 and 7. 
Table 2 Changes in venous diameter at a cuff pressure of $45 \mathrm{~mm} \mathrm{Hg}$ after oral administration of placebo and $10 \mathrm{mg}$ dihydroergotamine, expressed as a percentage of control values, mean \pm s.e. mean, $n=9$, subjects no. 8-16.

\begin{tabular}{ccr}
\hline $\begin{array}{c}\text { Time } \\
\text { (h) }\end{array}$ & Placebo & Dihydroergot \\
0.5 & & \\
& -0.4 & -10.5 \\
1 & \pm 0.9 & \pm 2.7 \\
& -1.1 & -16.3 \\
1.5 & \pm 0.8 & \pm 3.4 \\
& +1.3 & -19.4 \\
2 & \pm 0.8 & \pm 3.6 \\
& -0.5 & -19.6 \\
3 & \pm 1.1 & \pm 4.0 \\
& -0.9 & -19.5 \\
4 & \pm 1.7 & \pm 5.0 \\
& -0.3 & -24.9 \\
6 & \pm 0.9 & \pm 3.5 \\
& -5.2 & -18.5 \\
8 & \pm 3.6 & \pm 4.8 \\
& -3.7 & -21.4 \\
& \pm 4.2 & \pm 5.4
\end{tabular}

on the back of the hand. This reduces the influence of hand movements or hand swelling on the actual measurement. A continuous recording of the diameter of the vein under a constant congestion pressure is possible. The technical procedures when carrying out the experiment are rather simple and do not need extensive preparation.

The results of the experiments with noradrenaline administered before and after local infusion of phentolamine show that the method is well suited for the study of interactions between agonists and antagonists on human veins in vivo.

Previous single-dose experiments using the optical technique have shown the 5-hydroxytryptamine antagonism of pizotifen on human hand veins in vivo (Aellig, 1978). Ergotamine in low doses was found to potentiate the constrictor effect of noradrenaline on isolated perfused rabbit ear and human temporal arteries (Carroll, Ebeling \& Glover 1974).

Interactions between 5-hydroxytryptamine and noradrenaline on the one hand and ergotamine and

\section{References}

AELLIG, W.H. (1974). Venoconstrictor effect of dihydroergotamine in superficial hand veins. Eur. J. clin. Pharmac., 7, 137-139.

AELLIG, W.H. (1978). Clinical-pharmacological experiments with pizotifen (Sanomigran $R$ ) on superficial hand veins in man. In Current Concepts in Migraine Research, ed. Greene, R. pp. 53-62. New York: Raven Press. pizotifen on the other hand have been investigated with our new technique (Aellig, 1981). The results show a parallel shift to the right of the 5-hydroxytryptamine dose-response curves typical for a competitive antagonism after local administration of $80 \mathrm{ng}$ of the 5-hydroxytryptamine antagonist pizotifen, but no displacement of the noradrenaline dose-response curves. Local infusion of $16 \mathrm{ng}$ of ergotamine had no influence on 5-hydroxytryptamine dose-response curves but potentiated the venoconstrictor effect of noradrenaline. These results support the usefulness of this method for investigating drug interactions.

The method also allows to study venoconstrictor effects after oral drug administration. Dihydroergotamine $(10 \mathrm{mg})$ administered orally produced a reduction in venous diameter at a congestion pressure of $45 \mathrm{~mm} \mathrm{Hg}$ of the same order of magnitude as that reported previously with the optical technique (Aellig, 1974). Contrary to the previous experiments, however, in which drug effects were measured for $2.5 \mathrm{~h}$ only, the present study was extended to $8 \mathrm{~h}$ after the administration of dihydroergotamine. The mean results after placebo show that venous diameter remains fairly constant for the first $\mathbf{4 h}$ after administration, and after 6 and $8 \mathrm{~h}$, no marked changes oocur either. The differences between the effects seen after dihydroergotamine and placebo were statistically significant at all times from $30 \mathrm{~min}$ onwards $(P<0.05$, paired $t$-test). Since there was practically no difference in the venoconstrictor effect of dihydroergotamine from 1.5 to $8 \mathrm{~h}$ after intake (apart from the slightly but not significantly higher value at $4 \mathrm{~h}$ ), the results also show the long duration of the venoconstrictor effect of dihydroergotamine after oral administration.

This new and rather simple experimental technique for recording the compliance of superficial hand veins in man may be useful not only for experiments in healthy volunteers, but also to study the interactions between various agonists and drugs given for chronic oral treatment of diseases such as hypertension or migraine.

I would like to thank Mr. H. Wohlfart for his great help in designing and compiling the experimental set-up; Mrs M. Frössl for her skillful technical assistance and Mrs M. Uebelmann for secretarial help.

AELLIG, W.H. (1979). Use of a linear variable differential transformer to measure compliance of human hand veins in situ. Br. J. clin. Pharmac., 8, 395P.

AELLIG, W.H. (1981). Agonists and antagonist of 5-HT on venomotor receptors. In Proceedings of the International Headache Congress 1980, eds. Critchley, M., Friedman, A.P., Sicuteri, F. \& Gorini, S. New York: Raven Press, in press. 
AMINU, J.M. \& VERE, D.W. (1972). The effects of oral propranolol on the distensibility of resting superficial veins in man. Clin. Sci., 42, 3P.

AMINU, J.M. \& VERE, D.W. (1978). A longitudinal study of the mechanisms of action of debrisoquine and propranolol. Br. J. clin. Pharmac., 6, 43-50.

CARROLL, P.R., EBELING, P.W. \& GLOVER, E. (1974). The responses of the human temporal and rabbit ear artery to 5-hydroxytrytamine and some of its antagonists. Aust. J. exp. Biol. med. Sci., 52, 813-823.

COLLIER, J.G., NACHEV, C. \& ROBINSON, B.F. (1972). Effect of catecholamines and other vasoactive substances on superficial hand veins in man. Clin. Sci., 43, 455-467.

DEL BIANCO, P.L. \& SICUTERI, F. (1978). Computerized venospasm: A method for exploring the neurovascular junction in man. J. Pharmac. Methods, 1, 329-340.

MÜLLER-SCHWEINITZER, E. (1974). Studies on the peripheral mode of action of dihydroergotamine in human and canine veins. Eur. J. Pharmac., 27, 231-237.
NACHEV, C., COLLIER, J.G. \& ROBINSON, B.F. (1971). Simplified method for measuring compliance of superficial veins. Cardiovasc. Res., 5, 147-156.

ROBINSON, B.F. (1978). Assessment of drugs on the venous system in man. Br. J. clin. Pharmac., 6, 381-386.

SCHAEVITZ, H. (1947). The linear variable differential transformer. Proc. Society for Experimental Stress Analysis, Cambridge Mass., 4, 79-88.

SICUTERI, F., DEL BIANCO, P.L., FANCIULLACCI, M. \& FRANCHI, G. (1964). Il test della venocostrizione per la misura della sensibilità alla 5-idrossitriptamina ed alle catecolamine nell' uomo. Boll. Soc. Ital. Biol. Sperim., 40, 1148-1150.

WHITE, C. de B. \& UDWADIA, B.P. (1975). $\beta$-adrenoceptors in the human dorsal hand vein, and the effects of propranolol and practolol on venous sensitivity to noradrenaline. Br. J. clin. Pharmac., 2, 99-105.

(Received June 3, 1980) 